\title{
FIMBRIAE AND INFECTIVITY IN SALMONELLA TYPHIMURIUM
}

\author{
J. P. Duguid, M. R. Darekar and D. W. F. Wheater \\ Bacteriology Department, University of Dundee, Scotland
}

\section{Plate XXIX}

EVIDENCE that the attachment of bacteria to mucosal epithelium may be an important step in the process of infection has been reviewed by Savage (1972). The filamentous appendages, type- 1 fimbriae, present in many commensal and pathogenic enterobacteria, make the bacteria strongly adhesive for intestinal epithelium and other kinds of cells, including erythrocytes (Duguid et al., 1955; Duguid, 1968). A possible role of fimbriae in promoting infection by shigellae, escherichiae and salmonellae was considered by Duguid and Gillies (1957), Duguid (1964) and Duguid, Anderson and Campbell (1966), but these authors concluded that fimbriae were not essential for infection because some strains in each pathogenic species were genotypically non-fimbriate. They thought, however, that the property of fimbrial adhesion to intestinal mucosa might be marginally advantageous to the bacteria, either by facilitating the establishment of infection or by prolonging carriage in the intestine.

We have now tried to demonstrate that fimbriae have such a role by comparing the results of challenging mice with Salmonella typhimurium bacteria of fimbriate $\left(\mathrm{Fim}^{+}\right)$and non-fimbriate $\left(\mathrm{Fim}^{-}\right)$genotypes. About $85 \%$ of strains of S. typhimurium from natural sources are $\mathrm{Fim}^{+}$and $15 \% \mathrm{Fim}^{-}$(Duguid et al., 1975), but we considered that unrelated $\mathrm{Fim}^{+}$and $\mathrm{Fim}^{-}$isolates would be unsuitable for comparison because any difference in their pathogenicity might be due to a genetic difference unassociated with fimbriation. We decided instead to compare Fim ${ }^{+}$and $\mathrm{Fim}^{-}$lines of bacteria descended from the same parent strain, the one line being derived by spontaneous mutation from the other. Two such lines are likely to be genetically identical except for their difference in Fim genotype. The Fim genotype is rather stable in S. typhimurium but Duguid et al. (1975) isolated spontaneous Fim ${ }^{+}$mutants from a few strains of biotypes termed "Non-FIRN Fim" " and we used one of these Fim" strains, no. 1566, and its Fim ${ }^{+}$mutant.

Although stable in Fim genotype, the Fim ${ }^{+}$strains of $S$. typhimurium are unstable in phenotype and vary readily between fimbriate and non-fimbriate phases. The proportion of bacteria in either phase is determined by the conditions of culture. Thus, cultures grown in aerobic static broth at $37^{\circ} \mathrm{C}$ for $24 \mathrm{~h}$ or longer contain many fimbriate bacteria, whilst cultures grown for only

Received 25 Mar. 1976; accepted 30 Mar. 1976.

J. MED. MICROBIOL. - VOL. 9 (1976) 
4-6 $\mathrm{h}$, so that they have barely or not quite completed the logarithmic phase of growth, contain very few (Duguid et al., 1966). Since we wished to observe the influence of the Fim phenotype of the bacteria inoculated into mice, as well as that of their Fim genotype, we made separate experiments with inocula of log-phase and stationary-phase bacteria.

The experiments were done by inoculating equal numbers of viable bacteria of the Fim ${ }^{+}$and $\mathrm{Fim}^{-}$strains into matched groups of mice and observing the number of mice becoming infected, as shown by culture of $S$. typhimurium from their faeces or tissues, the number of mice dying within 42 days after challenge and the duration of faecal excretion of $S$. typhimurium in the surviving mice. Inoculations were made into the mouth and conjunctiva to test the ability of the bacteria to infect through an intact epithelium, and into the peritoneum to test the virulence of the bacteria after their introduction into the tissues.

A preliminary account of some of these experiments (group 4) has been given by Darekar and Duguid (1972).

\section{MATERIALS AND METHODS}

\section{Bacteria}

The same Fim ${ }^{+}$and Fim ${ }^{-}$lines of S. typhimurium strain no. 1566 were used throughout. The parent strain had been isolated from a pig in Indiana, USA, and was received as an agar-stab culture (no. 2495-62) from Dr P. R. Edwards in 1962. It was Fim- and lacked $\mathrm{O}$-antigen 5. After the stab culture had been stored at ambient temperature for 2 months, a plating from it yielded a mixture of $\mathrm{Fim}^{+}$and $\mathrm{Fim}^{-}$colonies. One colony of each type was picked to prepare the master cultures for the experiments.

Examination by the methods of Duguid et al. (1966) showed that strain $1566 \mathrm{Fim}^{+}$had type-1 fimbriae with mannose-sensitive haemagglutinating activity and a strong adhesiveness for mouse, guinea-pig and human intestinal epithelium, whilst strain $1566 \mathrm{Fim}^{-}$had neither fimbriae nor haemagglutinating and adhesive properties. The Fim genotype of each strain was rather stable; Fim ${ }^{-}$mutants were never observed in cultures of the Fim $^{+}$strain and $\mathrm{Fim}^{+}$mutants appeared only rarely in cultures of the Fim ${ }^{-}$strain. Although the Fim ${ }^{+}$ mutants were sought by making haemagglutination tests on cultures grown for $48 \mathrm{~h}$ in aerobic static broth, where the conditions are strongly selective for Fim ${ }^{+}$bacteria (Old and Duguid, 1970), they were found in only five out of over a thousand such cultures of the Fimstrain.

The identity of the two strains in all observed characters except that of fimbriation confirmed that the Fim ${ }^{+}$strain was a mutant from the Fim ${ }^{-}$strain and not an unrelated contaminant of it. Both strains had the antigenic structure 4,12:i : 1,2 and both belonged to primary biotype 26 in the scheme of Duguid et al. (1975), the Fim ${ }^{+}$strain to full biotype $26 \mathrm{a}$ and the Fim - to full biotype 26b, which is the same as 26a but non-fimbriate. Examinations at the Enteric Reference Laboratory, Colindale, London, showed that both strains belonged to phage-type 1a in the scheme of Felix and Callow (1951) and phage-type 49 (provisional type U57) in an extended scheme (E. S. Anderson, unpublished).

The virulence of each strain was exalted by three passages in mice by intraperitoneal inoculation and recovery from the heart blood. Infected blood from the third mouse was diluted in nutrient broth and freeze-dried in ampoules. For each group of experiments the contents of an ampoule were plated and a colony was picked to a Dorset's egg slope which was incubated overnight and then stored at ambient temperature. The slope was subcultured in broth to provide fresh inocula for each experiment. 


\section{Media and incubation}

Nutrient broth ( $p \mathrm{H} \mathrm{7.3)} \mathrm{was} \mathrm{Oxoid} \mathrm{Lab-Lemco} \mathrm{beef} \mathrm{extract} 10 \mathrm{~g}$, Oxoid Bacteriological Peptone (L37) $10 \mathrm{~g}, \mathrm{NaCl} 5 \mathrm{~g}$ and water 1 litre; it was used in 10-ml volumes in test-tubes stoppered with cotton-wool.

MacConkey's lactose neutral-red bile-salt agar, deoxycholate citrate agar (DCA) and selenite $\mathrm{F}$ broth were as described by Cruickshank et al. (1975). Rhamnose minimal agar was the ammonia-salts medium of Davis and Mingioli (1950) with L-rhamnose $0 \cdot 3 \%$ instead of glucose and citrate as carbon sources.

Strontium chloride broth (Iveson and Mackay-Scollay, 1969) contained $\mathrm{SrCl}_{2} 6 \mathrm{~g}$, malachite green $0.004 \mathrm{~g}$, Bactotryptone (Difco) $0.5 \mathrm{~g}, \mathrm{KH}_{2} \mathrm{PO}_{4} 0.1 \mathrm{~g}, \mathrm{NaCl} 0.8 \mathrm{~g}$ and distilled water $111 \mathrm{ml} ; 10-\mathrm{ml}$ volumes were sterilised in tubes at $100^{\circ} \mathrm{C}$ for $30 \mathrm{~min}$.

Saline solution was $0.85 \% \mathrm{NaCl}$. Phosphate-buffered saline $(p \mathrm{H} \mathrm{7.2)}$ was this saline with $\mathrm{K}_{2} \mathrm{HPO}_{4} 1.20 \mathrm{~g}, \mathrm{KH}_{2} \mathrm{PO}_{4} 0.34 \mathrm{~g}$ and nutrient broth $20 \mathrm{ml}$ added per litre. Alkaline buffer solution $(p \mathrm{H} \mathrm{8.4})$ was $\mathrm{Na}_{2} \mathrm{HPO}_{4} 1.0 \mathrm{~g}$, nutrient broth $5 \mathrm{ml}$ and distilled water $95 \mathrm{ml}$.

Cultures were incubated aerobically at $37^{\circ} \mathrm{C}$ without shaking.

\section{Mice}

Mice of the LAC Grey strain were obtained from the Laboratory Animals Centre, Carshalton. On receipt, each batch was isolated for 14 days while some animals were killed and proved by culture of their tissues to be free from salmonellae. When given inoculations, they were at least 4 weeks old and mostly weighed between 25 and $30 \mathrm{~g}$. Groups for comparative challenge were matched by mean of body weights and comprised equal numbers of males and females. Except for the mice infected intraperitoneally in the group-4 experiments, which were caged in groups of five, each mouse was caged separately in a plastic box roofed with a metal grill bearing a food-hopper and water-bottle. Drinking water and a diet of commercial food pellets were provided ad libitum. Food-hoppers and water-bottles were not exchanged between cages during an experiment. Sawdust litter in the cages was changed twice a week with care to avoid scattering.

After inoculation, the mice were transferred to a fresh experimental room maintained at $18-20^{\circ} \mathrm{C}$. The cages were placed side by side in four tiers of racks. Mice infected with Fim ${ }^{+}$ bacteria were kept at one side of the room and those infected with Fim- bacteria at the opposite side. In most experiments, a few uninoculated " control " mice were kept for 42 days in cages placed at random among those of the infected mice.

\section{Inocula for mice}

The $\mathrm{Fim}^{+}$and $\mathrm{Fim}^{-}$bacteria inoculated in any experiment were taken from cultures grown under the same conditions. The choice of conditions depended on whether the Fim ${ }^{+}$ bacteria were to be used in their fimbriate $\left(\mathrm{Fim}^{+} \mathrm{F}\right)$ or non-fimbriate $\left(\mathrm{Fim}^{+} \mathrm{N}\right)$ phase.

Log-phase cultures (Fim ${ }^{+} \mathrm{N}$ bacteria). A tube of nutrient broth was seeded lightly from the stock slope culture and incubated for $24 \mathrm{~h}$. The broth culture was mixed to distribute the pellicle and deposit and $0.5 \mathrm{ml}$ was added to a tube containing $9.5 \mathrm{ml}$ of fresh broth at $37^{\circ} \mathrm{C}$. Immediately, $0 \cdot 1 \mathrm{ml}$ of the diluted culture was inoculated into each of several tubes of broth at $37^{\circ} \mathrm{C}$, which were incubated until, after about $4 \mathrm{~h}$, one of them gave a turbidity reading between $0 \cdot 13$ and $0 \cdot 18$ on a Spekker photoelectric absorptiometer. This culture was diluted with fresh broth to a turbidity of 0.10 (equivalent to a count of about $1.0 \times 10^{8}$ bacteria per $\mathrm{ml}$ ) and then used directly for the oral inoculations. It was further diluted with phosphatebuffered saline $(p \mathbf{H} 7 \cdot 2)$ for the conjunctival and intraperitoneal inoculations.

Stationary-phase cultures (Fim ${ }^{+} \boldsymbol{F}$ bacteria). A tube of broth was seeded from the stock culture and incubated for $48 \mathrm{~h}$. The culture was mixed and $0.05 \mathrm{ml}$ inoculated into a second tube of broth which was incubated for $24 \mathrm{~h}$. The second culture was mixed and diluted with fresh broth to give a turbidity of $0 \cdot 10$. The inocula for the mice were prepared by further 
dilution with phosphate-buffered saline ( $p \mathrm{H} \mathrm{7 \cdot 2)}$ or, in the group-4 experiments, alkalinebuffer solution ( $p \mathrm{H} 8 \cdot 4)$.

Examination of inocula. The diluted cultures were held at $18-20^{\circ} \mathrm{C}$ for about $1 \mathrm{~h}$ while the inoculations were made, and viable counts were then done by spreading replicate $0 \cdot 1-\mathrm{ml}$ volumes of appropriate dilutions on nutrient-agar plates. The mean number of viable bacteria inoculated per mouse (tables I and II) was estimated from these counts. A portion of each culture was killed by the addition of formaldehyde and stored at $4^{\circ} \mathrm{C}$ for later observations of fimbriation and haemagglutinating power (HP) by the methods of Duguid et al. (1966).

\section{Inoculation methods}

Oral inoculation. An Agla micrometer syringe with a blunted needle was used to deliver a $0.01-\mathrm{ml}$ drop of suspension containing the required number of bacteria, e.g., $10^{6}$ or $10^{7}$. The mouse was held on its back with its mouth open and the drop made to touch the front teeth, when it at once passed back into the mouth.

Conjunctival inoculation. A $0.002-\mathrm{ml}$ drop of suspension containing the required number of bacteria, e.g., $10^{4}$ or $10^{5}$, was touched on to the conjunctiva while the eye was held open by gentle traction on the lids; it at once spread throughout the conjunctival sac. Care was taken to avoid touching or abrading the conjunctiva with the needle.

Intraperitoneal inoculation. About 10 bacteria in $0.1 \mathrm{ml}$ of suspension were injected into the lower right abdomen.

Alkaline-buffer inoculations. In the experiments of group 4 the mice were deprived of food and water for $24 \mathrm{~h}$ before inoculation and the inoculum was suspended in alkaline-buffer

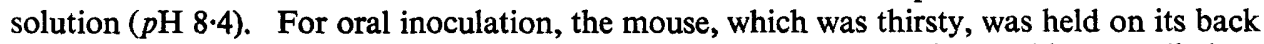
and allowed to swallow three $0.02-\mathrm{ml}$ drops of suspension expelled from a blunt needle into the open mouth. For conjunctival inoculation a $0.02-\mathrm{ml}$ drop was placed on the open eye.

For the sake of uniformity, all inoculations were done by the same operator (J. P. D.).

\section{Examination of mice after challenge}

Culture of faeces. Faeces were collected from the surviving mice at 7, 10, 20, 30, 40, 50, $60,70,80,90,100,110$ and 120 days after inoculation. In the experiments of group 4, samples were collected at 15 instead of 10 days and additional samples at 1 and 3 days. Each mouse was placed in a separate tray made of clean paper and kept there until it defaecated.

In the experiments of groups 2 and 3, two faecal pellets were dispersed in $0.6 \mathrm{ml}$ of broth, and $0.1 \mathrm{ml}$ of the mixture was inoculated on to a DCA plate, $0.2 \mathrm{ml}$ into selenite broth and $0.2 \mathrm{ml}$ into strontium chloride broth. After incubation for $24 \mathrm{~h}$ the selenite culture was plated on rhamnose minimal agar and the strontium-chloride culture on DCA. The rhamnose medium was used because many mice carried proteus bacteria that could grow in the selenite broth and form pale colonies on DCA, but could not grow on the rhamnose medium. $S$. typhimurium grew well on the rhamnose medium and any colonies seen after $48 \mathrm{~h}$ were subcultured on MacConkey's agar.

In the experiments of group 1 the faeces were plated directly on DCA and enriched in selenite broth before subculture on DCA. In those of group 4 the faeces were plated directly on MacConkey's agar and enriched in selenite broth before subculture on MacConkey's agar.

Killing of animals. Mice not yielding $S$. typhimurium from faecal samples at 7, 10, 20, 30 and 40 days were killed with chloroform at 42 days. Those yielding $S$. typhimurium from one or more samples were kept until they died naturally or survived to 120 days, when they were killed.

Culture of tissues. After killing or natural death a few drops of blood from the heart were inoculated into nutrient broth. Splenic pulp was smeared on MacConkey's agar and cut pieces of spleen and liver were put into tubes of broth. A segment of lower ileum, with its contents, was cut into pieces and placed in selenite broth. After incubation for $24 \mathrm{~h}$ the selenite cultures were plated on DCA and after $48 \mathrm{~h}$ the broth cultures on MacConkey's agar. 
TABLE I

Infections and deaths in groups of mice given oral, conjunctival (Conj.) or intraperitoneal (IP) inoculations of log-phase bacteria of the Fim ${ }^{+}$or Fim ${ }^{-}$line of Salmonellatyphimurium strain 1566 in 10 experiments

\begin{tabular}{|c|c|c|c|c|c|c|c|}
\hline \multirow[b]{2}{*}{ Line* } & \multirow[b]{2}{*}{$\underset{\text { no. } \dagger}{\text { Experiment }}$} & \multicolumn{2}{|c|}{ Inoculation } & \multicolumn{3}{|c|}{ Number of mice } & \multirow{2}{*}{$\begin{array}{l}\text { Mean number } \\
\text { of days to } \\
\text { death within } \\
42 \text { days }\end{array}$} \\
\hline & & Route & $\begin{array}{c}\text { Number } \\
\text { of } \\
\text { bacteria } \ddagger\end{array}$ & $\begin{array}{l}\text { given } \\
\text { inocula- } \\
\text { tion }\end{array}$ & $\begin{array}{l}\text { becoming } \\
\text { infected }\end{array}$ & $\begin{array}{c}\text { dying } \\
\text { within } \\
42 \text { days }\end{array}$ & \\
\hline \multirow[t]{2}{*}{$\mathrm{Fim}^{+}$} & $\begin{array}{r}1 \\
2 \\
3 \\
4 \\
5 \\
6 \\
7 \\
8 \\
9 \\
10\end{array}$ & $\begin{array}{l}\text { Oral } \\
\text { Oral } \\
\text { Oral } \\
\text { Oral } \\
\text { Oral } \\
\text { Conj. } \\
\text { Conj. } \\
\text { Conj. } \\
\text { Conj. } \\
\text { Conj. }\end{array}$ & $\begin{array}{r}800000 \\
490000 \\
680000 \\
820000 \\
890000 \\
8800 \\
8300 \\
11000 \\
4900 \\
9600\end{array}$ & $\begin{array}{l}20 \\
20 \\
20 \\
20 \\
20 \\
20 \\
20 \\
20 \\
20 \\
20\end{array}$ & $\begin{array}{l}10 \\
4 \\
11 \\
12 \\
13 \\
11 \\
15 \\
12 \\
17 \\
13\end{array}$ & $\begin{array}{r}6 \\
3 \\
7 \\
11 \\
11 \\
5 \\
7 \\
4 \\
8 \\
9\end{array}$ & $\begin{array}{l}10 \cdot 5 \\
14 \cdot 7 \\
10 \cdot 1 \\
16 \cdot 0 \\
10 \cdot 5 \\
12.8 \\
21 \cdot 7 \\
12 \cdot 8 \\
19 \cdot 0 \\
14 \cdot 3\end{array}$ \\
\hline & $\begin{array}{r}1 \\
2 \\
3 \\
4 \\
5 \\
6 \\
7 \\
8 \\
9 \\
10\end{array}$ & $\begin{array}{l}\text { IP } \\
\text { IP } \\
\text { IP } \\
\text { IP } \\
\text { IP } \\
\text { IP } \\
\text { IP } \\
\text { IP } \\
\text { IP } \\
\text { IP }\end{array}$ & $\begin{array}{r}8.0 \\
4.9 \\
6.8 \\
8.2 \\
8.9 \\
8.8 \\
8 \cdot 3 \\
11.0 \\
4 \cdot 9 \\
9 \cdot 6\end{array}$ & $\begin{array}{r}8 \\
8 \\
8 \\
10 \\
10 \\
5 \\
5 \\
5 \\
5\end{array}$ & $\begin{array}{r}8 \\
8 \\
7 \\
10 \\
10 \\
5 \\
4 \\
5 \\
4 \\
10\end{array}$ & $\begin{array}{r}7 \\
8 \\
5 \\
10 \\
10 \\
4 \\
4 \\
4 \\
4 \\
10\end{array}$ & $\begin{array}{r}13 \cdot 1 \\
11.8 \\
11 \cdot 2 \\
7 \cdot 4 \\
6.8 \\
8.0 \\
8 \cdot 3 \\
8 \cdot 5 \\
13.0 \\
8 \cdot 9\end{array}$ \\
\hline $\mathrm{Fim}^{-}$ & $\begin{array}{r}1 \\
2 \\
3 \\
4 \\
5 \\
6 \\
7 \\
8 \\
9 \\
10\end{array}$ & $\begin{array}{l}\text { Oral } \\
\text { Oral } \\
\text { Oral } \\
\text { Oral } \\
\text { Oral } \\
\text { Conj. } \\
\text { Conj. } \\
\text { Conj. } \\
\text { Conj. } \\
\text { Conj. }\end{array}$ & $\begin{array}{r}470000 \\
320000 \\
1190000 \\
730000 \\
1140000 \\
6900 \\
7400 \\
13000 \\
6400 \\
11800\end{array}$ & $\begin{array}{l}20 \\
20 \\
20 \\
20 \\
20 \\
20 \\
20 \\
20 \\
20 \\
20\end{array}$ & $\begin{array}{r}6 \\
11 \\
12 \\
5 \\
12 \\
7 \\
13 \\
19 \\
19 \\
16\end{array}$ & $\begin{array}{r}4 \\
6 \\
5 \\
4 \\
9 \\
6 \\
7 \\
5 \\
10 \\
8\end{array}$ & $\begin{array}{l}12 \cdot 0 \\
18 \cdot 5 \\
11 \cdot 6 \\
12 \cdot 0 \\
11 \cdot 7 \\
18 \cdot 7 \\
21 \cdot 6 \\
20 \cdot 6 \\
16 \cdot 6 \\
18 \cdot 4\end{array}$ \\
\hline & $\begin{array}{r}1 \\
2 \\
3 \\
4 \\
5 \\
6 \\
7 \\
8 \\
9 \\
10\end{array}$ & $\begin{array}{l}\text { IP } \\
\text { IP } \\
\text { IP } \\
\text { IP } \\
\text { IP } \\
\text { IP } \\
\text { IP } \\
\text { IP } \\
\text { IP } \\
\text { IP }\end{array}$ & $\begin{array}{r}4.7 \\
3.2 \\
11.9 \\
7.3 \\
11 \cdot 4 \\
6.9 \\
7.4 \\
13.0 \\
6.4 \\
11.8\end{array}$ & $\begin{array}{r}8 \\
8 \\
8 \\
10 \\
10 \\
5 \\
5 \\
5 \\
5 \\
10\end{array}$ & $\begin{array}{r}7 \\
6 \\
8 \\
9 \\
10 \\
4 \\
5 \\
5 \\
5 \\
9\end{array}$ & $\begin{array}{r}6 \\
6 \\
7 \\
9 \\
9 \\
10 \\
4 \\
5 \\
5 \\
5 \\
9\end{array}$ & $\begin{array}{r}9 \cdot 2 \\
11 \cdot 0 \\
8 \cdot 6 \\
6 \cdot 7 \\
9 \cdot 8 \\
10 \cdot 0 \\
9.8 \\
7 \cdot 2 \\
8 \cdot 0 \\
12 \cdot 9\end{array}$ \\
\hline
\end{tabular}

* Fim ${ }^{+}$bacteria were mainly in the non-fimbriate phase; only $1-3 \%$ bore fimbriae.

$\dagger$ Bacteria from the same Fim ${ }^{+}$or Fim- culture were used for the intraperitoneal and the oral or conjunctival inoculations in the same experiment.

$\ddagger$ The mean number inoculated per mouse is given (see Methods). 
Examination of cultures. MacConkey's and DCA plates were examined for pale (nonlactose-fermenting) colonies and a pale colony from each positive culture was plated on nutrient agar. If the subculture did not swarm, i.e., was not Proteus, it was tested by agglutination with salmonella $\mathrm{O} 4$ antiserum, and a colony was subcultured on a Dorset egg slope for later testing for haemagglutination.

Assessment of number of infections and deaths. All surviving mice were kept for 42 days after inoculation and the number dying in this period was recorded. The number of mice in which the inoculation succeeded in establishing an infection was assessed as the aggregate of the animals belonging to one or more of the following categories: (1) mice dying within 42 days after inoculation, (2) mice yielding $S$. typhimurium from any of the tissues cultured after killing or death, and (3) mice yielding $S$. typhimurium from a culture of faeces collected at 7 , $10,20,30$ or 40 days after inoculation.

\section{RESULTS \\ Log-phase Fim $^{+} \mathrm{N}$ and Fim ${ }^{-}$bacteria}

The Fim ${ }^{+}$and Fim $^{-}$strains were tested in mice by the inoculation of bacteria from log-phase (4-h) broth cultures. The Fim ${ }^{+}$cultures were mainly in the non-fimbriate phase $\left(\mathrm{Fim}^{+} \mathrm{N}\right)$, being only very weakly haemagglutinating (HP $=5-20)$ and containing only about 1 or $2 \%$ of bacteria with fimbriae. Table I shows the results of 10 experiments in which groups of mice were given either oral or conjunctival inoculations and other groups given intraperitoneal inoculations from the same cultures. The numbers of infections and deaths and the mean times to death in the groups receiving similar inocula were reasonably consistent from experiment to experiment, showing that the procedures were well standardised. The results of these 10 experiments aggregated with those of another four on groups of 20 mice challenged intraperitoneally are given in table II (group-1 experiments).

\section{Stationary-phase Fim $^{+} \mathrm{F}$ and Fim $^{-}$bacteria}

The Fim ${ }^{+}$and $\mathrm{Fim}^{-}$strains were tested by the inoculation of bacteria from stationary-phase (24-h) broth cultures. The Fim ${ }^{+}$cultures were substantially in the fimbriate phase $\left(\mathrm{Fim}^{+} \mathrm{F}\right)$, being strongly haemagglutinating $(\mathrm{HP}=100-400)$ and containing between about 10 and $40 \%$ of fimbriate bacteria (fig. 1). The aggregated results in three groups of experiments (groups 2-4) are shown in table II. Group 2 comprised seven experiments in which the bacteria were inoculated at dose levels ("low level ") similar to those in group 1. Group 3 comprised 11 experiments in which the oral and conjunctival inocula were 10-fold larger (" high level "), whilst group 4 comprised nine experiments in which the oral inoculum was only one-tenth as large as in groups 1 and 2 , but the bacteria were protected from gastric acidity by suspension in alkaline buffer.

\section{Deaths from infection}

All deaths observed within 42 days after challenge were attributed to $S$. typhimurium infection because the unchallenged, control animals, except one that became cross-infected, remained alive and because $S$. typhimurium could 
TABLE II

Infections and deaths in mice given oral, conjunctival (Conj.) or intraperitoneal (IP) inoculations of log-phase or stationary-phase bacteria of the Fim ${ }^{+}$or Fim- line of Salmonella typhimurium strain 1566: aggregated results in four groups of experiments with different kinds of inocula*

\begin{tabular}{|c|c|c|c|c|c|c|}
\hline \multicolumn{3}{|c|}{ Inoculation } & \multicolumn{3}{|c|}{ Number of mice } & \multirow{2}{*}{$\begin{array}{l}\text { Mean number } \\
\text { of days to } \\
\text { death within } \\
42 \text { days } \dagger\end{array}$} \\
\hline Route & $\begin{array}{c}\text { Line of } \\
\text { bacteria* }\end{array}$ & $\begin{array}{l}\text { Mean number } \\
\text { of bacteria }\end{array}$ & $\begin{array}{l}\text { given } \\
\text { inocula- } \\
\text { tion }\end{array}$ & $\begin{array}{l}\text { becoming } \\
\text { infected }\end{array}$ & $\begin{array}{l}\text { dying } \\
\text { within } \\
42 \text { days }\end{array}$ & \\
\hline
\end{tabular}

Group 1: Log-phase bacteria in neutral medium

\begin{tabular}{llr|rrrr} 
Oral & Fim $^{+}$ & 740000 & 100 & 50 & 38 & $12 \cdot 3$ \\
& Fim $^{-}$ & 770000 & 100 & 46 & 28 & $13 \cdot 2$ \\
Conj. & Fim $^{+}$ & 8500 & 100 & 68 & 33 & $16 \cdot 6$ \\
& Fim $^{-}$ & 9100 & 100 & 74 & 36 & $18 \cdot 9$ \\
IP & Fim $^{+}$ & 10 & 154 & 140 & 130 & $9 \cdot 4$ \\
& Fim $^{-}$ & 11 & 154 & 137 & 128 & $9 \cdot 4$
\end{tabular}

Group 2: Stationary-phase bacteria in neutral medium, low-level dose

\begin{tabular}{llr|rrrr} 
Oral & Fim $^{+}$ & 1200000 & 50 & 12 & 10 & $18 \cdot 6$ \\
& Fim $^{-}$ & 1500000 & 50 & 9 & 8 & $17 \cdot 5$ \\
Conj. & Fim $^{+}$ & 14000 & 50 & 15 & 12 & $15 \cdot 3$ \\
& Fim $^{-}$ & 14000 & 50 & 16 & 10 & $16 \cdot 1$ \\
IP & Fim $^{+}$ & 12 & 50 & 47 & 47 & $9 \cdot 3$ \\
& Fim $^{-}$ & 13 & 50 & 48 & 48 & $7 \cdot 4$
\end{tabular}

Group 3: Stationary-phase bacteria in neutral medium, high-level dose

\begin{tabular}{llr|rrrr} 
Oral & Fim $^{+}$ & 14000000 & 50 & 40 & 30 & $15 \cdot 4$ \\
& Fim $^{-}$ & 14000000 & 50 & 34 & 25 & $12 \cdot 0$ \\
Conj. & Fim $^{+}$ & 150000 & 50 & 43 & 24 & $18 \cdot 2$ \\
& Fim $^{-}$ & 140000 & 50 & 42 & 27 & $14 \cdot 3$ \\
IP & Fim $^{+}$ & 15 & 50 & 42 & 38 & $10 \cdot 7$ \\
& Fim $^{-}$ & 14 & 50 & 48 & 47 & $9 \cdot 6$
\end{tabular}

Group 4: Stationary-phase bacteria in alkaline buffer

\begin{tabular}{llr|rrrr} 
Oral & Fim $^{+}$ & 99000 & 280 & 68 & 47 & $17 \cdot 6$ \\
& Fim $^{-}$ & 98000 & 280 & 46 & 28 & $14 \cdot 4$ \\
Conj. & Fim $^{+}$ & 32000 & 197 & 88 & 51 & $19 \cdot 6$ \\
& Fim $^{-}$ & 33000 & 197 & 75 & 29 & $17 \cdot 6$ \\
IP & Fim $^{+}$ & 10 & 115 & 101 & 95 & $10 \cdot 4$ \\
& Fim $^{-}$ & 9 & 115 & 102 & 82 & 11.0
\end{tabular}

\footnotetext{
* Stationary-phase cultures of the Fim ${ }^{+}$line contained $10-40 \%$ of fimbriate bacteria; log-phase $\mathrm{Fim}^{+}$cultures were mainly in the non-fimbriate phase and contained only $1-3 \%$ of fimbriate bacteria.

$\dagger$ Mean for mice dying within 42 days after inoculation. A further 57 of the mice infected orally or conjunctivally died between 43 and 120 days; 30 of these had received Fim ${ }^{+}$and 27 Fim $^{-}$bacteria.
}

be cultured from the tissues of almost every animal that died. Cultures were seeded with heart-blood, spleen, liver and ileum from 975 of the 1051 mice that died within 42 days and $S$. typhimurium was recovered from all but three animals. The only mice kept alive after 42 days were 242 animals that had excreted S. typhimurium in the faeces at $7,10,20,30$ or 40 days after oral or conjunctival challenge; 57 of them died between 43 and 120 days and $S$. typhimurium was cultured from the tissues of 56 of the 57 .

The times to death varied widely between the different animals in the same inoculation groups. The shortest and longest times were 4 and 40 days after 
intraperitoneal, 7 and 118 days after oral, and 6 and 119 days after conjunctival challenge. In most experiments the mean time to death of the mice dying within 42 days was about 10 days for intraperitoneal, 15 days for oral, and 17 days for conjunctival challenge.

\section{Number of infections}

The number of mice that became infected (tables I and II) was calculated as the sum of those that died within 42 days or yielded S. typhimurium from the tissues post mortem or yielded $S$. typhimurium from faeces collected between 7 and 40 days. Six mice that died within 42 days after oral or conjunctival challenge and 63 that died after intraperitoneal challenge neither yielded $S$. typhimurium from the faeces nor were examined post mortem, but for the reasons given in the preceding section were regarded as having died from $S$. typhimurium infection.

Most of the mice yielding S. typhimurium in cultures post mortem did so from more than one of the tissues examined. Positive cultures were most commonly obtained from the spleen, but usually also from the heart-blood, liver or ileum, and often from all four tissues. Since no animal died before 4 days and few animals gave positive cultures from the ileum alone, our record of the number of infections was not inflated by the inclusion of animals having only a transient intestinal contamination during the first 3 days after inoculation (see below).

Control mice. In all, 95 unchallenged mice were kept during the first 42 days of experiments in cages placed beside those of mice challenged with the $\mathrm{Fim}^{+}$strain and 95 were kept beside mice challenged with the Fim ${ }^{-}$strain. All but one of the 190 animals survived until 42 days and, when then killed, were shown by culture to be free from salmonella infection. The exceptional animal, which was kept beside mice infected with the Fim ${ }^{-}$strain, became infected with that strain and died at 29 days. The finding that only this one control animal became infected showed that the experimental conditions gave little opportunity for cross-infection between adjacent cages.

\section{Faecal excretion of $S$. typhimurium}

The numbers of isolations of $S$. typhimurium obtained from the faeces of surviving infected mice at different times from 7 to 120 days after oral or conjunctival inoculation are shown in table III. The pattern of the results was similar for the oral and conjunctival inoculations and for the log-phase and stationary-phase inocula, and the results of the different kinds of experiments are therefore given in aggregate. For simplicity of presentation, the results for 15 days in the group-4 experiments are included with those for 10 days in the other experiments.

The results for 7, 10 and 20 days were incomplete, since in a few experiments faeces were not collected from any animal on one or more of these occasions. Thus, at 7 days only 622 out of the total of 726 infected mice were examined. 


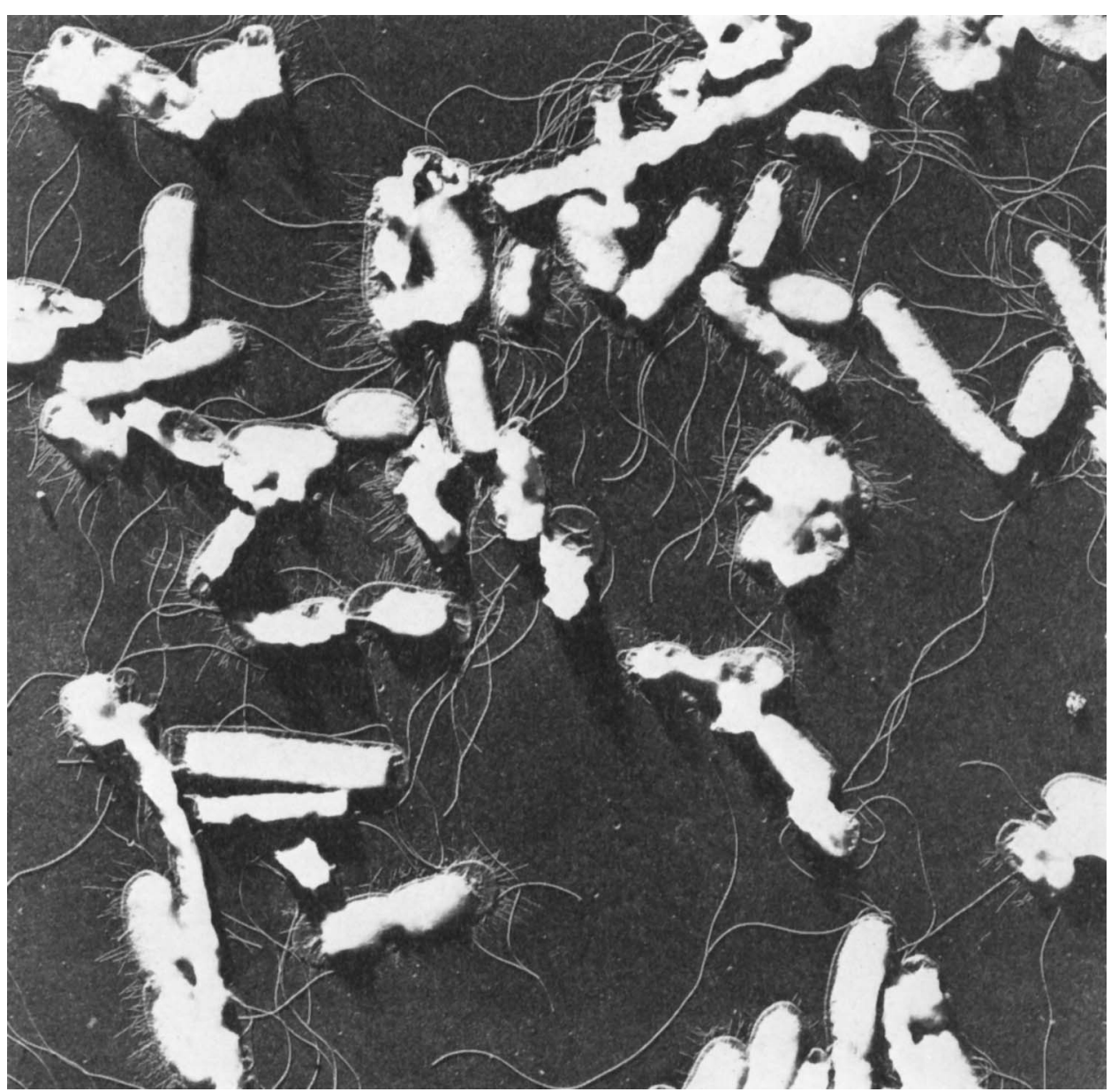

FIG. 1.-Fimbriate and non-fimbriate bacteria in a metal-shadowed film of a fimbriate-phase 24-h broth culture of the Fim ${ }^{+}$strain of Salmonella typhimurium. The numerous short filaments are fimbriae and the longer filaments are flagella. About $50 \%$ of fimbriate bacteria are present in this field, but a smaller proportion was present in most other fields. Electronmicrograph. $\times 7300$. 
TABLE III

Faecal excretion of Salmonella typhimurium by mice infected with Fim $^{+}$or Fim- bacteria; aggregate results for surviving infected mice examined by faecal culture after oral or conjunctival inoculation in the experiments recorded in table II

\begin{tabular}{|c|c|c|c|c|}
\hline \multirow{3}{*}{$\begin{array}{l}\text { Number of } \\
\text { days after } \\
\text { inoculation }\end{array}$} & \multicolumn{4}{|c|}{ Number of mice infected with } \\
\hline & \multicolumn{2}{|c|}{$\mathrm{Fim}^{+}$bacteria $(384 / 877)^{*}$} & \multicolumn{2}{|c|}{ Fim $^{-}$bacteria $(342 / 877)^{*}$} \\
\hline & $\begin{array}{l}\text { examined } \\
\text { by culture }\end{array}$ & S. typhimurium & $\begin{array}{l}\text { examined } \\
\text { by culture }\end{array}$ & S. typhimurium \\
\hline $\begin{array}{r}7 \\
10 \\
20 \\
30 \\
40 \\
50 \\
60 \\
70 \\
80 \\
90 \\
100 \\
110 \\
120\end{array}$ & $\begin{array}{r}322 \\
247 \\
177 \\
167 \\
133 \\
117 \\
107 \\
102 \\
99 \\
92 \\
89 \\
87 \\
83\end{array}$ & $\begin{array}{r}176 \\
168 \\
130 \\
115 \\
68 \\
49 \\
45 \\
33 \\
30 \\
26 \\
23 \\
26 \\
17\end{array}$ & $\begin{array}{r}300 \\
247 \\
174 \\
165 \\
144 \\
110 \\
103 \\
96 \\
93 \\
82 \\
80 \\
78 \\
76\end{array}$ & $\begin{array}{r}133 \\
143 \\
88 \\
79 \\
44 \\
28 \\
27 \\
20 \\
17 \\
11 \\
12 \\
6 \\
6\end{array}$ \\
\hline $\begin{array}{l}\text { Any; total of } \\
\text { examinations } \\
\text { and isolations }\end{array}$ & 1822 & 906 & 1748 & 614 \\
\hline
\end{tabular}

* Number of mice successfully infected/number of mice challenged.

Since, however, the deficiencies applied equally to the $\mathrm{Fim}^{+}$and $\mathrm{Fim}^{-}$groups, they did not detract from the comparative value of the results.

A single positive result was recorded for a faecal sample regardless of whether S. typhimurium was isolated from one or more than one of its plate and enrichment cultures. Selenite enrichment gave $25 \%$ more isolations, and strontium chloride enrichment gave $40 \%$ more isolations than did direct plating on DCA, whilst the combination of methods detected more positive samples than any one method alone. Although direct plating gave fewer isolations than the liquid enrichment cultures, it resembled them in giving nearly $50 \%$ more isolations of the Fim ${ }^{+}$strain than of the Fim ${ }^{-}$strain. For this reason, the excess of Fim $^{+}$over Fim ${ }^{-}$isolations shown for the combination of methods (table III) cannot be attributed to the known selective advantage of $\mathrm{Fim}^{+}$over Fim ${ }^{-}$ bacteria in static liquid cultures.

Different animals varied widely in their pattern of excretion of S. typhimurium. Some gave positive cultures on most or all occasions of testing, others did so only intermittently and yet others did so on only a few early occasions, thereafter remaining free from infection. Nearly $80 \%$ of the mice shown by their death or positive post-mortem culture to have been infected by the oral or conjunctival inoculation were found to excrete S. typhimurium between 7 
and 40 days. These proven excretors were $309(81 \%)$ of the 384 mice infected with Fim $^{+}$bacteria and $249(73 \%)$ of the 342 infected with Fim ${ }^{-}$bacteria. The minority of infected mice not found to excrete $S$. typhimurium included some that died before the first collection of faeces and some that gave only negative cultures in the few tests before their killing at 42 days or earlier death.

In the experiments in which early examinations were made, many animals were found to excrete $S$. typhimurium at 1 or 3 days after oral or conjunctival inoculation but not on any later occasion. Very few (four of 80 ) of these transient excretors were found to be infected when killed at 42 days and the positive cultures of the majority probably reflected a temporary persistence of inoculated bacteria in the intestinal lumen without penetration into the tissues. Results for faeces collected at 1 and 3 days were therefore disregarded as evidence of infection.

By contrast, the finding of $S$. typhimurium in the faeces at 7 days or later was good evidence of infection. Of 551 mice that gave such positive cultures and were later examined post mortem, $422(77 \%)$ showed $S$. typhimurium in cultures from their tissues. These 422 infected mice included 365 of 366 that died before 120 days and 57 of 185 killed at 120 days. The 128 excretors found to be uninfected at 120 days presumably had freed themselves from the infection during the long period of their survival.

\section{Fim genotype of isolates from mice}

Haemagglutination tests were done on 1091 isolates of $S$. typhimurium recovered from 283 mice that had been challenged with $\mathrm{Fim}^{+}$bacteria and 1196 isolates from 308 mice challenged with Fim ${ }^{-}$bacteria; $40 \%$ of these isolates were from faeces and $60 \%$ from tissues, $77 \%$ were collected within 42 days after inoculation and $23 \%$ between 43 and 120 days.

All but four of the 2287 isolates were found to have the same Fim genotype as that of the strain originally inoculated into the mouse from which the isolate was obtained. The four exceptions were $\mathrm{Fim}^{+}$isolates grown from the liver and spleen of two mice killed 120 days after the inoculation of $\mathrm{Fim}^{-}$bacteria. They may have arisen by mutation from the Fim ${ }^{-}$bacteria growing in the mouse's body or have been acquired by cross-infection from a mouse infected with $\mathrm{Fim}^{+}$bacteria. Whatever their origin, their rarity shows that the Fim genotype of the bacteria was very stable in vivo and that cross-infection between animals was infrequent.

A different kind of anomaly was shown by five cultures grown from mice that died after challenge with $\mathrm{Fim}^{-}$bacteria. These cultures, which were on Dorset slopes, consisted mainly of Fim ${ }^{-}$bacteria but contained also a small proportion $(<1 \%)$ of Fim $^{+}$bacteria, which were detected when they outgrew the $\mathrm{Fim}^{-}$and gave haemagglutination reactions in subcultures in broth. The Fim $^{+}$bacteria appeared to be mutants that had arisen during storage of the Fim $^{-}$slope cultures, and it is noteworthy that such mutants were found in only five of the $1192 \mathrm{Fim}^{-}$cultures examined. 


\section{Discussion}

Although about $15 \%$ of strains of $S$. typhimurium are Fim-, most of them belong to the fimbriae-, inositol- and rhamnose-negative (FIRN) biotypes, nos. 29-32, which are derived mainly from avian sources and are found only rarely in mammals other than patients with food-poisoning (Duguid et al. 1975). Among non-FIRN strains from natural, mainly mammalian sources, only about $2 \%$ are $\mathrm{Fim}^{-}$, and this infrequency suggests that the $\mathrm{Fim}^{-}$strains are less competent parasites of mammals than the Fim ${ }^{+}$strains. Our experiments with $\mathrm{Fim}^{+}$and $\mathrm{Fim}^{-}$bacteria derived from the same mammalian nonFIRN Fim ${ }^{-}$strain were designed to demonstrate such a difference.

\section{Fimbriation and infection}

Intraperitoneal challenge. The results of challenge were greatly influenced by the route of inoculation. With either strain, the intraperitoneal inoculation of a small number (101) of bacteria caused many more infections and deaths than the conjunctival or oral inoculation of a much larger number $\left(10^{4}-10^{7}\right)$. This difference probably reflected the efficacy of the body's surface defences against conjunctival and oral infection, which were by-passed by the intraperitoneal injection, and it emphasised the importance of any properties of the infecting bacteria that may help them to penetrate the surface epithelium.

Fimbriation did not seem to influence the progress of the systemic infection after the bacteria had been given access to the tissues by intraperitoneal inoculation, for the two strains caused similar numbers of infections and deaths. Of a total of 369 mice challenged intraperitoneally with the Fim ${ }^{+}$strain, 330 became infected and 310 died, whilst of 369 challenged with the Fim ${ }^{-}$strain 335 became infected and 305 died (table II). The mean times to death in the two groups were virtually identical.

Oral challenge. In contrast to the lack of difference between the strains when the inoculation was intraperitoneal, the $\mathrm{Fim}^{+}$strain showed a clear advantage over the Fim $^{-}$when it was by mouth. This finding is as to be expected if the role of fimbriae is to help the bacteria to adhere to and penetrate the alimentary mucosa.

The advantage of the Fim ${ }^{+}$bacteria was not seen in every experiment, but was apparent in the aggregate results of each of the four groups of experiments (table II) as well as in those of the whole series. Of a total of 480 mice challenged orally with the Fim ${ }^{+}$strain, $170(35 \%)$ became infected and $125(26 \%)$ died within 42 days, whilst of 480 challenged with the Fim ${ }^{-}$strain only 135 $(28 \%)$ became infected and $89(18.5 \%)$ died. The difference between these numbers of infections is significant at the level of $2.5 \%\left(\chi^{2}=5.9\right)$ and that between the numbers of deaths at the level of $1 \%\left(\chi^{2}=7 \cdot 8\right)$. If, as it seems, this observed ability of the Fim ${ }^{+}$bacteria to infect $25 \%$ more animals than the Fim $^{-}$bacteria is due to their possession of fimbriae, the property of fimbriation clearly has a substantial survival value.

Conjunctival challenge. The conjunctival resembles the oral route of inoculation in requiring the bacteria to invade through an intact epithelium, 
but when inoculated by this route the $\mathrm{Fim}^{+}$bacteria did not cause significantly more infections than the $\mathrm{Fim}^{-}$(table II). The difference from the results of oral inoculation is puzzling, but it must be recognised that the conditions of infection by the two routes are not identical. In keeping with Moore's (1957) finding for $S$. enteritidis infection in guinea-pigs, we found that infection took place much more readily through the conjunctiva than through the mouth. Thus, in groups 1-3, the inoculation of bacteria on to the conjunctiva caused about as many infections and deaths as the inoculation of a hundred-fold larger doses of bacteria by mouth. The advantage of the conjunctival over the oral route may have been due in part to its enabling the bacteria to reach the tissues without exposure to the acid in the stomach. The antagonistic effect of gastric acidity on oral inocula was shown by the finding that similar rates of infection were caused by smaller doses of bacteria when these were protected by suspension in alkaline buffer (cf. groups 2 and 4, table II).

Fimbrial phase. The results of challenge did not seem to be influenced by the fimbriation phenotype of the inoculated Fim ${ }^{+}$bacteria. The results of the experiments of group 1, in which the Fim ${ }^{+}$bacteria were mainly in the non-fimbriate phase, were much the same as those of groups $2-4$, in which the Fim $^{+}$bacteria were in the fimbriate phase (table II). Since the Fim ${ }^{+}$ bacteria can readily change their phase within a few hours' growth in artificial culture, any effect of the phase of the bacteria in the inoculum given to the mice could be expected to apply only in the first few hours of the infection. Subsequently, a mixture of fimbriate-phase and non-fimbriate-phase bacteria would probably be present in the mouse's body. We had no means of observing the phase of the bacteria while they were in the tissues, for fimbriae are difficult to see in tissue sections under the electron microscope and the phase may change rapidly when the bacteria are isolated in culture.

Adhesion to mucosa. The attachment of S. typhimurium to the ileal mucosa $8 \mathrm{~h}$ after intragastric inoculation in gnotobiotic mice has been observed by Tannock, Blumershine and Savage (1975). Attachment took place not only with the Fim $^{+}$strain LT2, but also with two mutant strains which, though haemagglutinating, did not show fimbriae in cultures examined with the electron microscope. These interesting findings are difficult to interpret and the possibility must be considered either that the mutants were able to form fimbriae under the conditions in vivo or that they produced the haemagglutinin in a non-filamentous form.

The observations of Duguid et al. (1966) on mixtures of cells and bacteria in wet films showed that fimbriae are responsible for the ability of the bacteria to adhere quickly and firmly to the surface of mucosal cells and that wild-type Fim $^{-}$strains of $S$. typhimurium lack the power of quick, firm adhesion. Infection, however, must be procured by a different mechanism of association between the bacteria and the mucosa. That mechanism, which may depend on the character of the bacterial O-antigen, cannot depend primarily on the presence of fimbriae or a haemagglutinin, because non-haemagglutinating Fim $^{-}$strains, such as strain 1566 , cause many infections both in nature and in the laboratory. The mechanism of infective association apparently does 
not involve an adhesion sufficiently rapid and strong to be noticeable, like fimbrial adhesion, during the brief observation of a wet film. Its reinforcement by fimbrial adhesion may therefore facilitate infection.

\section{Fimbriation and faecal dissemination}

The properties likely to have a survival value for a salmonella include not only those that help it to invade and infect its host, but also those that promote its excretion in the faeces and thus its opportunities for dissemination to fresh hosts. Our observations on excretion of the bacteria were made to discover whether fimbriation had an effect of the latter kind. We found that mice infected with the Fim ${ }^{+}$strain, whether by mouth or conjunctiva, excreted $S$. typhimurium more freely than mice infected with the Fim ${ }^{-}$strain (table III). In equal totals of 877 mice challenged in the four groups of experiments 384 became infected with the Fim ${ }^{+}$strain and excreted it in the faeces on 906 observed occasions, whilst 342 became infected with the Fim ${ }^{-}$strain and excreted it on only 614 occasions. The excess of $\mathrm{Fim}^{+}$over $\mathrm{Fim}^{-}$excretions was due partly to the greater number of mice that became infected with the $\mathrm{Fim}^{+}$strain, but partly also to longer periods of carriage and a greater number of positive excretions per infected mouse in the Fim ${ }^{+}$group.

The proportions of surviving infected mice in the Fim ${ }^{+}$and $\mathrm{Fim}^{-}$groups that yielded positive faecal cultures at different times after challenge are compared in fig. 2. We are indebted to Dr R. A. Brown, Department of Mathematics, University of Dundee, for fitting to the two sets of data graphs of the form: $y=a e^{-\lambda t}$. The value $y$ represents the proportion of animals excreting $S$. typhimurium, $t$ is the time in days, and $a$ and $\lambda$ are constants to be determined. Since the graph of this type of equation declines continuously from $t=0$, whilst the observed proportions of positive excretions rose to a peak at 10-20 days after challenge, and since not all mice were examined at the periods before 40 days, the data for the periods before 40 days were not used in obtaining the fitted curves and $t$ was taken as the number of days after day 40 .

The fitted curve for the Fim ${ }^{+}$group is $y=47 e^{-0.01 t}$ and that for the Fim ${ }^{-}$ group is $y=34 e^{-0.018 t}$. The constant $\lambda$ represents the rate of reduction in the proportion of positive excretions and it is seen to be only about half as great in the Fim ${ }^{+}(0.01)$ as in the Fim ${ }^{-}$group (0.018). The standard error of the difference between the rates is approximately 0.0024 and the actual difference observed is more than three times as great. A $t$ test with 14 degrees of freedom shows that the observed difference is significant at the $1 \%$ level.

If, as our results suggest, the possession of fimbriae enables a Fim ${ }^{+}$strain of $S$. typhimurium to obtain about $50 \%$ more opportunities for faecal dissemination than those of a Fim ${ }^{-}$strain, the advantage would seem fully sufficient to account for the large preponderance of $\mathrm{Fim}^{+}$strains in mammalian sources The explanation of the more persistent excretion of the Fim ${ }^{+}$bacteria may be that their intermittent, fimbriae-mediated adhesion to the walls of the biliary and intestinal tracts helps to sustain their colonisation of these tracts in face of the downward flow of luminal contents. 


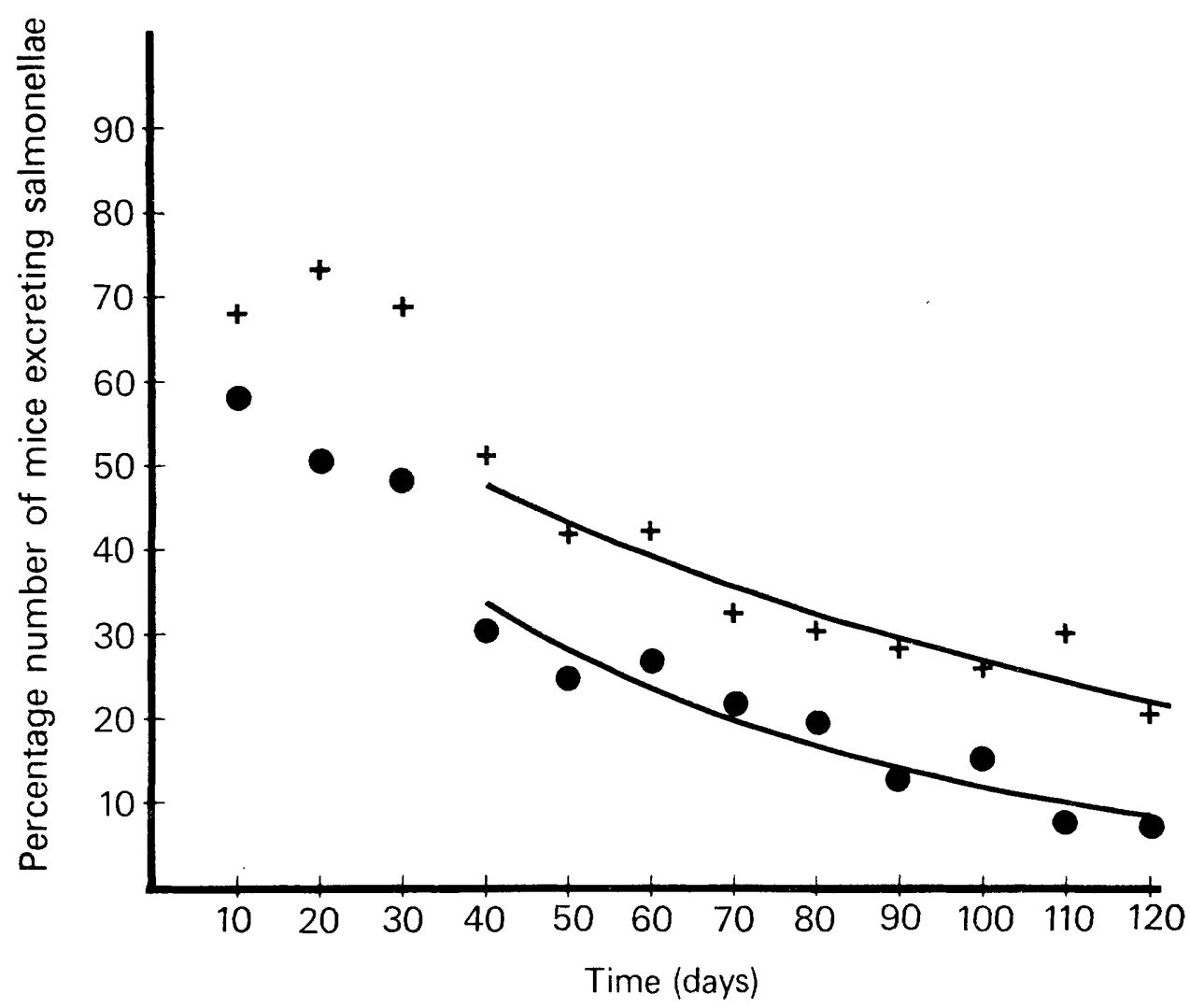

FIG. 2.-The proportions of surviving infected mice that excreted $S$. typhimurium in the faeces at different periods after challenge with the $\mathrm{Fim}^{+}(+)$or $\mathrm{Fim}^{-}$strain (O). The data are those for oral or conjunctival challenge given in table III and the graphs are fitted to the data for 40 days and later according to equations given in the text.

\section{SUMMARY}

A genotypically non-fimbriate $\left(\mathrm{Fim}^{-}\right)$strain of Salmonella typhimurium and a genotypically fimbriate $\left(\mathrm{Fim}^{+}\right)$strain derived from it by spontaneous mutation were compared for pathogenicity in mice. The two strains caused similar numbers of infections and deaths in groups of mice challenged by intraperitoneal inoculation, and nearly similar numbers in groups challenged by inoculation on to the conjunctiva, but the $\mathrm{Fim}^{+}$strain caused many more infections (plus $26 \%$ ) and deaths (plus $40 \%$ ) than the Fim ${ }^{-}$strain when the inoculation was by mouth.

Faecal cultures were made at intervals up to 120 days in the mice surviving after oral or conjunctival challenge and $S$. typhimurium was isolated more commonly from the animals challenged with the $\mathrm{Fim}^{+}$strain $(906$ isolations from 384 animals infected out of 877 challenged) than from those challenged with the Fim $^{-}$strain (614 isolations from 341 animals infected out of 877 challenged). The greater opportunity for faecal dissemination enjoyed by 
Fim $^{+}$bacteria may account for the preponderance of Fim $^{+}$over Fim ${ }^{-}$strains of $S$. typhimurium found in mammalian sources.

We are grateful to Dr R. A. Brown for statistical advice and to Mr Douglas Phin and Miss Jennifer Beaumont for technical assistance.

\section{REFERENCES}

Cruickshank, R., Duguid, J. P., Marmion, B. P. and Swain, R. H. A. 1975. Medical microbiology, 12th ed., Edinburgh and London, vol. 2, pp. 125-127.

Darekar, M. R. AND Duguid, J. P. 1972. The influence of fimbriation on the infectivity of Salmonella typhimurium. Proc. Indian Acad. Sci. B, 75, 283.

Davis, B. D. AND Mingioli, E. S. 1950. Mutants of Escherichia coli requiring methionine or vitamin B12. J. Bact., 60, 17.

Duguid, J. P. 1964. Functional anatomy of Escherichia coli with special reference to enteropathogenic E. coli. Rev. lat.-amer. Microbiol., 7, Suppl. 13-14, p. 1.

Duguid, J. P. 1968. The function of bacterial fimbriae. Arch. Immun. Thér. exp., 16, 173.

Duguid, J. P., Anderson, E. S., Alfredsson, G. A., Barker, R. AND Old, D. C. 1975. A new biotyping scheme for Salmonella typhimurium and its phylogenetic significance. J. med. Microbiol., 8, 149.

Duguid, J. P., Anderson, E. S. ANd CAmpbell, I. 1966. Fimbriae and adhesive properties in salmonellae. J. Path. Bact., 92, 107.

Duguid, J. P. AND Gillies, R. R. 1957. Fimbriae and adhesive properties in dysentery bacilli. J. Path. Bact., 74, 397.

Duguid, J. P., Smith, I. W., Dempster, G. ANd Edmunds, P. N. 1955. Non-flagellar filamentous appendages (" fimbriae") and haemagglutinating activity in Bacterium coli. J. Path. Bact., 70, 335.

Felix, A. ANd Callow, B. R. 1951. Paratyphoid-B Vi-phage typing. Lancet, 2, 10.

IVESON, J. B. AND MACKAY-SCOLLAY, E. M. 1969. Strontium chloride and strontium selenite enrichment broth media in the isolation of Salmonella. J. Hyg., Camb., 67, 457.

MoORE, B. 1957. Observations pointing to the conjunctiva as the portal of entry in salmonella infection of guinea-pigs. J. Hyg., Camb., 55, 414.

Old, D. C. AND Duguid, J. P. 1970. Selective outgrowth of fimbriate bacteria in static liquid medium. J. Bact., 103, 447.

SAVAGE, D. C. 1972. Survival on mucosal epithelia, epithelial penetration and growth in tissues of pathogenic bacteria. In Microbial pathogenicity in man and animals (22nd Symp. Soc. gen. Microbiol.) edited by H. Smith and J. H. Pearce, Cambridge, p. 25.

Tannock, G. W., Blumershine, R. V. H. and Savage, D. C. 1975. Association of Salmonella typhimurium with, and its invasion of, the ileal mucosa in mice. Infect. Immun., 11,365 . 